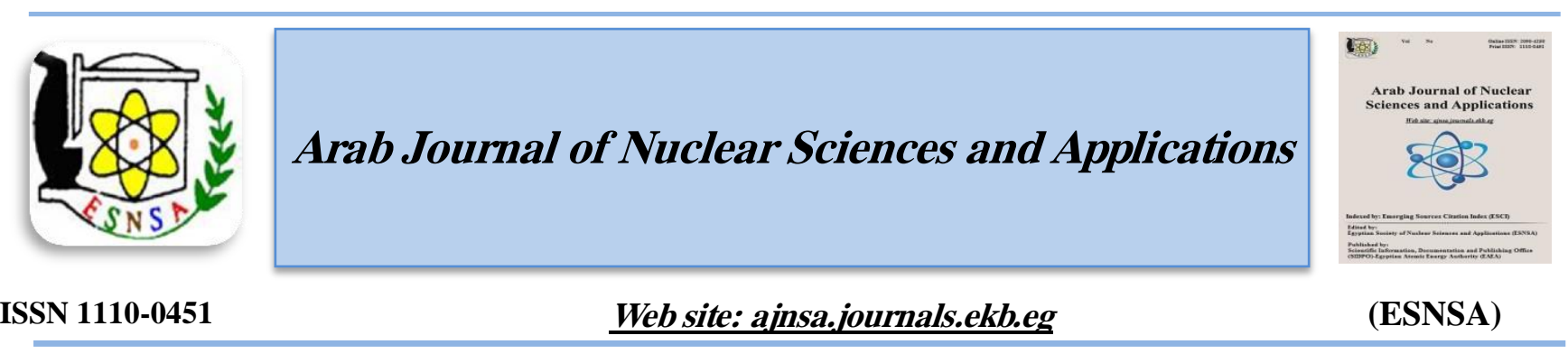

\title{
Evaluation of ENDF/B-VI.8 and ENDF/B-VII.0 Nuclear Data Libraries Using OSMOSE Samples of MINERVE Reactor
}

\author{
Hesham Shahbunder ${ }^{1,2, *}$ \\ ${ }^{I}$ Physics Department, Faculty of Science, Ain Shams University, Cairo, Egypt \\ ${ }^{2}$ Physics Department, College of Sciences and Humanities, Prince Sattam Bin Abdulaziz University, Al- \\ Kharj, Saudi Arabia
}

Received $06^{\text {th }}$ Jul. 2019 The evaluation of nuclear data libraries is an important tool to develop nuclear technology. To achieve Accepted $16^{\text {th }}$ Dec. 2019 this goal, OSMOSE program utilized samples that are composed of separated actinides which contain isotopes of americium, plutonium, uranium, and thorium. By inserting those samples in the core configuration of MINERVE reactor, they can be used for improvement of nuclear cross-section databases by cross checking their calculated reactivity worth per each sample using several nuclear data library versions and experimental measurements. The present study investigated the effect of the used nuclear data library on the calculated reactivity of MINERVE reactor with several OSMOSE samples employed in R1-UO2, R1-UO2, and R1-MOX core configurations. The study performed a comparison between the calculated effective multiplication factor using MCNPX code with ENDF/BVI.8 and ENDF/BVII.0 nuclear data libraries. Moreover, the relative difference between the calculated reactivity worth by ENDF/BVI.8 and ENDF/BVII.0 was examined and discussed using available experimental results of the relevant core.

Keywords: MCNPX, ENDF/B-VI.8, ENDF/B-VII.O, MINERVE, OSMOSE, Multiplication factor, Reactivity

\section{Introduction}

The development of nuclear technologies depends on building and improving nuclear data that provide an accurate numerical simulation of the nuclear reaction to obtain reliable design calculations. This is an essential requirement for safety and economic operation of these technologies. The basic data include energydependent cross-sections for reactions of many combinations of projectile and target, the atomic and nuclear properties of the nuclear excited states, and the associated radioactive decay data. Although the nuclear data and computational tools used for the present nuclear reactors have been extended to a high level of progress, the advanced types of reactors still require a further improvement in those tools and data, especially for employing unconventional nuclear fuel such as plutonium and minor actinides as a part of nuclear waste management and future design of nuclear systems.

Addressing the above issues, several studies have been going on to test and validate nuclear data libraries such as ENDF/B-VI.0, ENDF/B-VII.0, ENDF/B-VII.1, JENDL-3.3, JEFF-3.0, and JEFF3.1 using Monte Carlo transport codes MCNP, MCNPX, and others [1-6]. The experimental programs in MINERVE reactor [7-9] are designed to develop the integral absorption cross-sections of heavy isotopes and actinides. One of those important programs is the oscillation in MINERVE of isotopes in eupraxic spectra program

Corresponding author: ihesham@msn.com

DOI: 10.21608/ajnsa.2019.14381.1228

(C) Scientific Information, Documentation and Publishing Office (SIDPO)-EAEA 
(OSMOSE) with the goal of improving the calculations of neutronic parameters of advanced nuclear fuels via oscillation measurements in the MINERVE facility on samples that contain the separated actinides of americium, plutonium, uranium, and thorium isotopes. The investigations have undergone in a variety of neutron spectrum including thermal, epithermal and fast spectra.

The purpose of this work is to study the effect of using different ENDF nuclear data library on the calculated effective multiplication factor and reactivity worth of MINERVE reactor with several OSMOSE samples. The calculations are performed by MCNPX code with ENDF/BVI.8 and ENDF/BVII.0 nuclear data libraries, in R1-UO2, R1-UO2, and R1-MOX core configurations. The final results are tested by comparison to available experimental measurements.

\section{Minerve Reactor}

MINERVE is an experimental pool-type reactor, which operates at low power of $100 \mathrm{~W}$. The dimension of the core is about $2.7 \times 2.7 \times 2.2$ meters which is submerged under water and divided into a driver zone that surrounds an experimental zone positioned in a central square cavity whose dimensions are about $0.70 \mathrm{~m}$ by 0.70 $\mathrm{m}$. The reactor core is moderated by distilled water and cooled by natural convection. The driver zone is fueled by uranium of $90-93 \mathrm{wt} \%$ enrichment, with aluminum clad, and divided into about 30 elements surrounded by a graphite reflector. The experimental zone is fueled by uranium of $3 \mathrm{wt} \%$ enrichment and used to control the neutron spectrum and conduct experiments. Specific and detailed description of the driver and experimental zones in MINREVE reactor is found in previous studies [10-12].

Osmose samples are employed in MINERVE reactor to enhance the nuclear cross-section databases by comparative calculations and measurements of the reactivity per each sample [13]. The samples are composed of separated actinide including isotopes of americium ${ }^{241} \mathrm{Am}$, $\left.{ }^{243} \mathrm{Am}\right)$, plutonium $\left({ }^{238} \mathrm{Pu},{ }^{239} \mathrm{Pu},{ }^{240} \mathrm{Pu},{ }^{241} \mathrm{Pu}\right.$, $\left.{ }^{242} \mathrm{Pu}\right)$, uranium $\left({ }^{233} \mathrm{U},{ }^{234} \mathrm{U},{ }^{236} \mathrm{U}\right)$ and thorium $\left({ }^{232} \mathrm{Th}\right)$. The isotopic composition of OSMOSE samples are shown in Table 1 [14]. The crosssectional view of the samples is shown in Figure (1), with more dimensional parameters found in the previous studies $[10,15,16]$. The samples are inserted individually in the core center for conducting experiment and necessary measurements.

The present study investigates three core configurations of MINERVE, which are R1-UO2, R2-UO2, and R1-MOX, shown in Figures (2, 3, and 4 , respectively). The experimental zone of R1$\mathrm{UO} 2$ contains 776 fuel rods of $\mathrm{UO}_{2}$ with a void in the center of the lattice. The same configuration applies for R2-UO2 experimental zone except for removing 8 fuel rods that surround the central void. The configuration of R1-MOX experimental zone is also similar to that of R1-UO2 but with 156 $\mathrm{UO}_{2}$ fuel rods, which surrounds the central void, being replaced by mixed oxide fuel rods (MOX) that are mainly composed of $\mathrm{PuO}_{2}$ with $\mathrm{Pu}$ of 3-4 $\mathrm{wt} \%$. The fuel and characteristic neutron spectrum of each core are shown in Table (2).

\section{Mcnpx Model}

In the present work, MCNPX code [17] with ENDF/B-VI.8 data library [18] and ENDF/ BVII.0 data library [19] are used in the calculation to obtain the neutron multiplication factor $k_{\text {eff }}$ and reactivity worth. The radial and side view of the MCNPX model of MINERVE core are presented in Figures (5 and 6), showing the main experimental and driver zones. The core configurations R1-UO2, R2-UO2, and R1-MOX were modeled using MCNPX and eigenvalue calculations were executed with a number of histories of 35 million including 250 active cycles. The standard deviation in sigma was less than 1.9E-4 for all core calculations

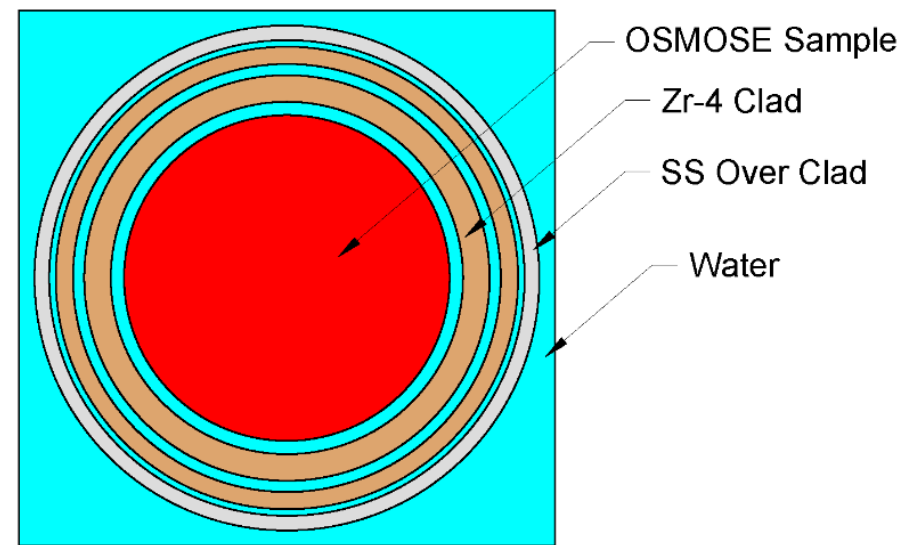

Fig. (1): Cross-sectional view of OSMOSE sample 
Table (1): Isotopic atom number percent of OSMOSE samples composition

\begin{tabular}{|c|c|c|c|c|c|c|c|c|c|c|c|c|c|c|c|c|}
\hline Sample & $\begin{array}{l}\underset{N}{N} \\
=\end{array}$ & 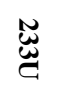 & $\underset{N}{N}$ & $\stackrel{N}{\text { N }}$ & ్ֶల & 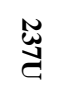 & $\underset{\infty}{\infty}$ & $\begin{array}{l}\underset{N}{\infty} \\
\underset{ٍ}{\mathscr{C}}\end{array}$ & 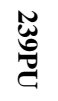 & 草 & $\stackrel{N}{\Xi}$ & $\stackrel{N}{\mathbb{N}}$ & $\begin{array}{l}\stackrel{N}{ \pm} \\
\Sigma\end{array}$ & $\begin{array}{l}\text { N } \\
\stackrel{D}{d} \\
3 \\
3\end{array}$ & 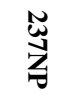 & 0 \\
\hline AM41_1 & 0.00 & 0.00 & 0.00 & 0.20 & 0.00 & 0.00 & 27.68 & 0.00 & 0.00 & 0.00 & 0.00 & 0.00 & 0.04 & 0.00 & 16.20 & 55.88 \\
\hline AM41_2 & 0.00 & 0.00 & 0.00 & 0.24 & 0.00 & 0.00 & 32.94 & 0.00 & 0.00 & 0.00 & 0.00 & 0.00 & 0.15 & 0.00 & 0.00 & 66.67 \\
\hline AM43 & 0.00 & 0.00 & 0.00 & 0.24 & 0.00 & 0.00 & 33.06 & 0.00 & 0.00 & 0.00 & 0.00 & 0.00 & 0.00 & 0.08 & 0.00 & 66.62 \\
\hline NP37_1 & 0.00 & 0.00 & 0.00 & 0.24 & 0.00 & 0.00 & 33.01 & 0.00 & 0.00 & 0.00 & 0.00 & 0.00 & 0.00 & 0.00 & 0.08 & 66.67 \\
\hline NP37_2 & 0.00 & 0.00 & 0.00 & 0.24 & 0.00 & 0.00 & 32.63 & 0.00 & 0.00 & 0.00 & 0.00 & 0.00 & 0.00 & 0.00 & 0.45 & 66.68 \\
\hline PU38 & 0.00 & 0.39 & 0.01 & 0.24 & 0.00 & 0.00 & 32.60 & 0.29 & 0.05 & 0.01 & 0.00 & 0.00 & 0.00 & 0.00 & 0.00 & 66.42 \\
\hline PU39 & 0.00 & 0.00 & 0.00 & 0.24 & 0.00 & 0.00 & 32.63 & 0.00 & 0.44 & 0.01 & 0.00 & 0.00 & 0.00 & 0.00 & 0.00 & 66.67 \\
\hline PU40 & 0.00 & 0.00 & 0.00 & 0.24 & 0.00 & 0.00 & 32.98 & 0.00 & 0.00 & 0.11 & 0.00 & 0.00 & 0.00 & 0.00 & 0.00 & 66.67 \\
\hline PU41 & 0.00 & 0.00 & 0.00 & 0.24 & 0.00 & 0.00 & 33.01 & 0.00 & 0.00 & 0.00 & 0.08 & 0.00 & 0.00 & 0.00 & 0.00 & 66.67 \\
\hline PU42 & 0.00 & 0.00 & 0.00 & 0.24 & 0.00 & 0.00 & 32.73 & 0.00 & 0.00 & 0.00 & 0.00 & 0.36 & 0.00 & 0.00 & 0.00 & 66.67 \\
\hline U233 & 0.00 & 0.00 & 0.01 & 0.24 & 0.00 & 0.00 & 33.09 & 0.00 & 0.00 & 0.00 & 0.00 & 0.00 & 0.00 & 0.00 & 0.00 & 66.65 \\
\hline U234 & 0.00 & 0.00 & 0.24 & 0.24 & 0.00 & 0.00 & 32.84 & 0.00 & 0.00 & 0.00 & 0.00 & 0.00 & 0.00 & 0.00 & 0.00 & 66.68 \\
\hline Unat & 0.00 & 0.00 & 0.00 & 0.24 & 0.01 & 0.00 & 33.08 & 0.00 & 0.00 & 0.00 & 0.00 & 0.00 & 0.00 & 0.00 & 0.00 & 66.67 \\
\hline URE & 0.00 & 0.00 & 0.02 & 1.33 & 0.30 & 0.00 & 31.67 & 0.00 & 0.00 & 0.00 & 0.00 & 0.00 & 0.00 & 0.00 & 0.00 & 66.67 \\
\hline TH232 & 33.32 & 0.00 & 0.00 & 0.00 & 0.00 & 0.00 & 0.00 & 0.00 & 0.00 & 0.00 & 0.00 & 0.00 & 0.00 & 0.00 & 0.00 & 66.68 \\
\hline U-TH232 & 1.62 & 0.00 & 0.00 & 0.23 & 0.00 & 0.00 & 31.48 & 0.00 & 0.00 & 0.00 & 0.00 & 0.00 & 0.00 & 0.00 & 0.00 & 66.68 \\
\hline
\end{tabular}

Table (2): Fuel and characteristic neutron spectra of MINERVE core configurations

\begin{tabular}{cccc}
\hline No. & Core configuration & Fuel type & Spectrum \\
\hline 1 & $\mathrm{R} 1-\mathrm{UO} 2$ & $\mathrm{UO}_{2}$ & PWR spectrum \\
2 & $\mathrm{R} 2-\mathrm{UO} 2$ & $\mathrm{UO}_{2}$ & Soft spectrum \\
3 & $\mathrm{R} 1-\mathrm{MOX}$ & ${\mathrm{MOX}\left[\mathrm{PUO}_{2}\right]}$ & PWR-MOX spectrum \\
\hline
\end{tabular}




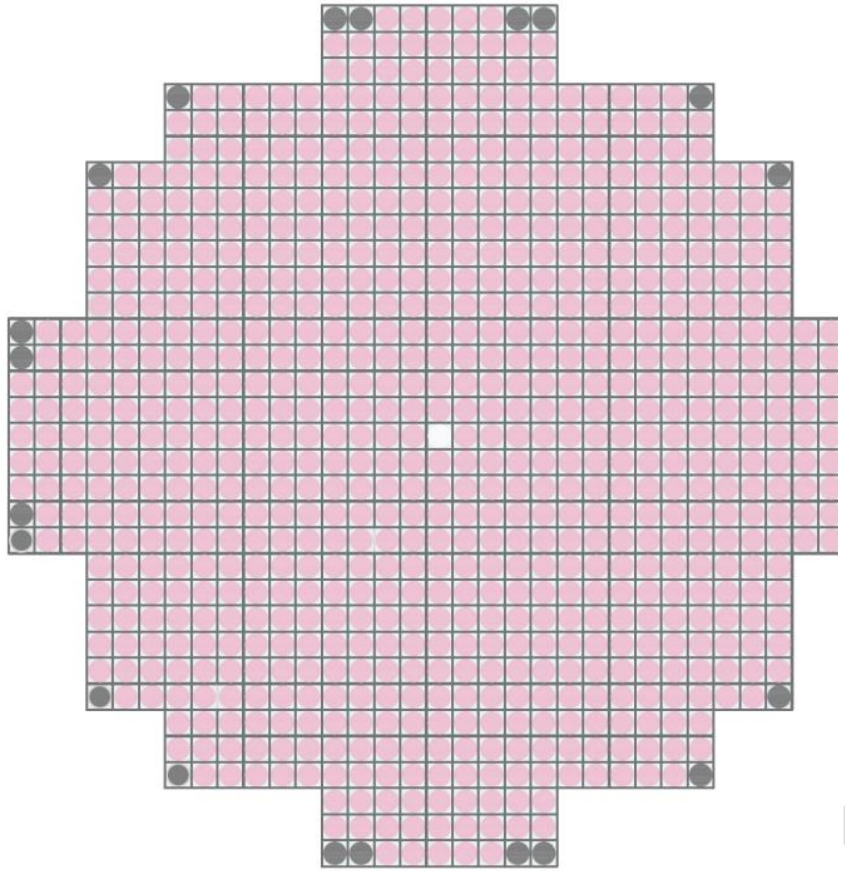

$\mathrm{UO}_{2}$ Pins

Al-Pins

Poline-overclad Element

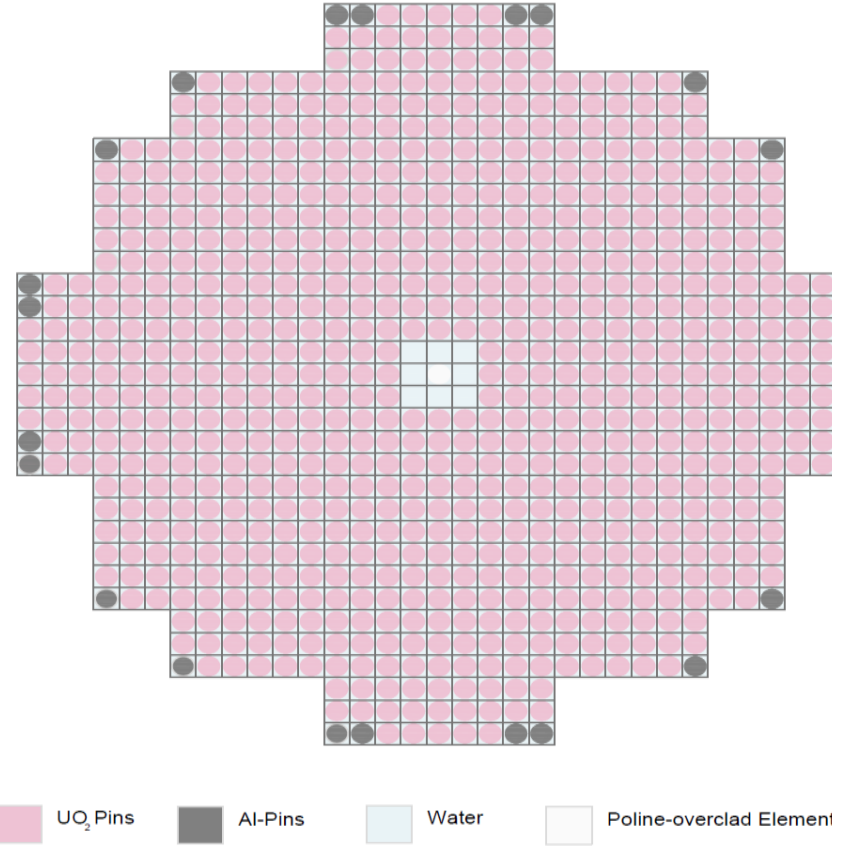

Fig. (3): Experimental zone of MINERVE core R2-UO2

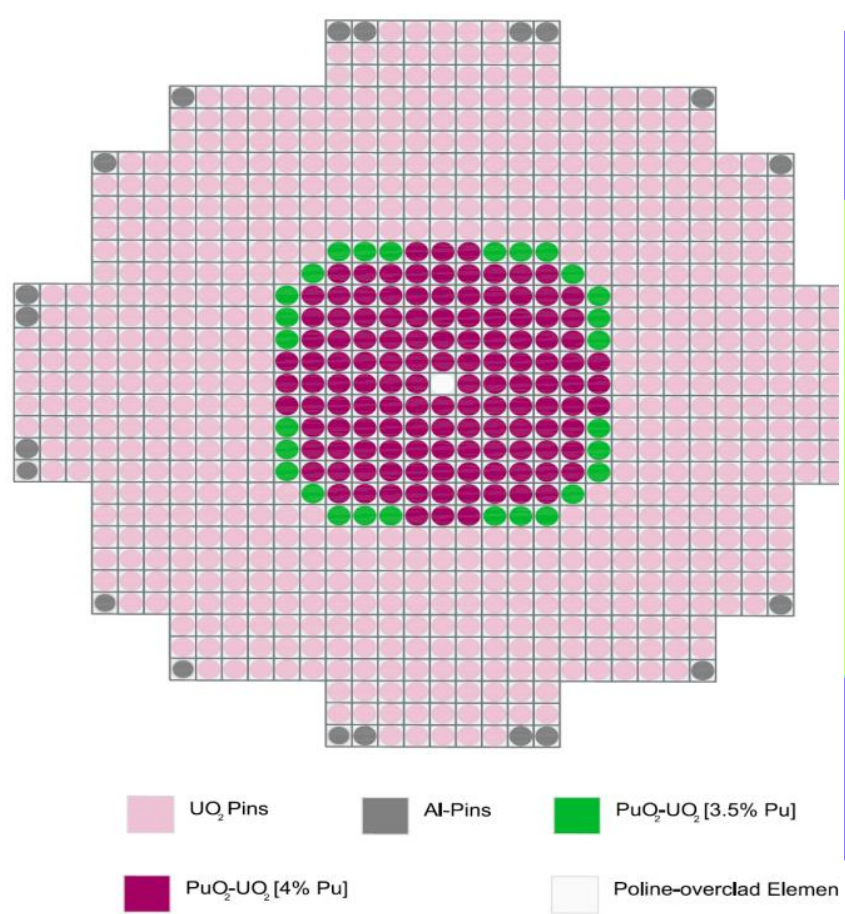

Fig. (4) Experimental zone of MINERVE core R1-MOX

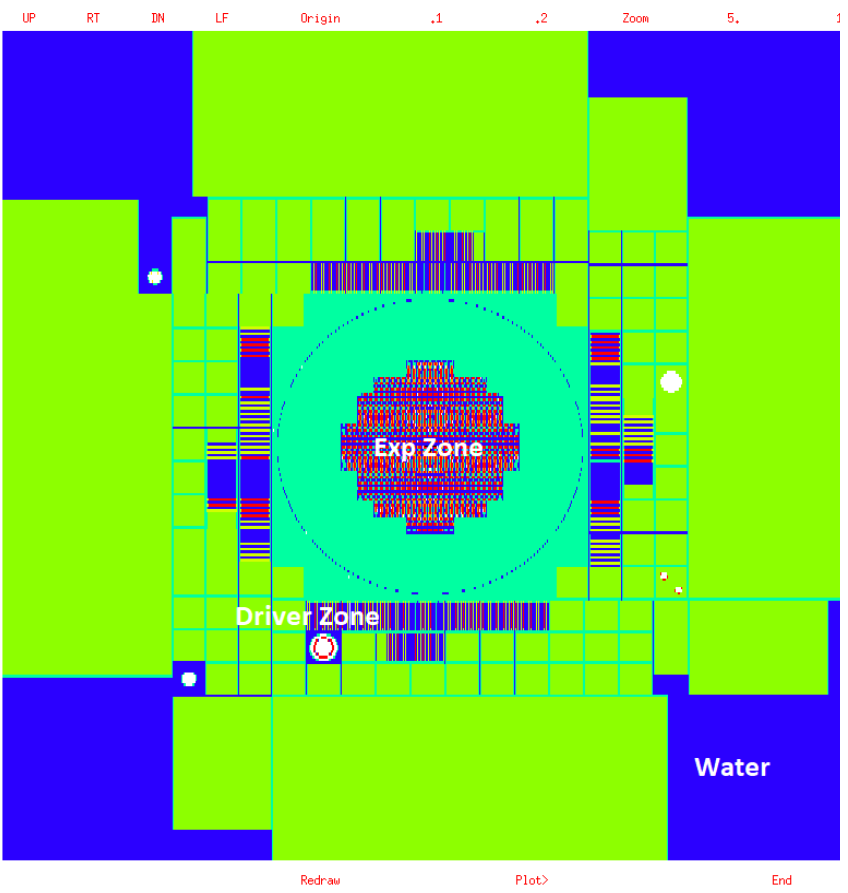

Fig. (5): MCNPX model radial view of MINERVE core experimental and driver zone 


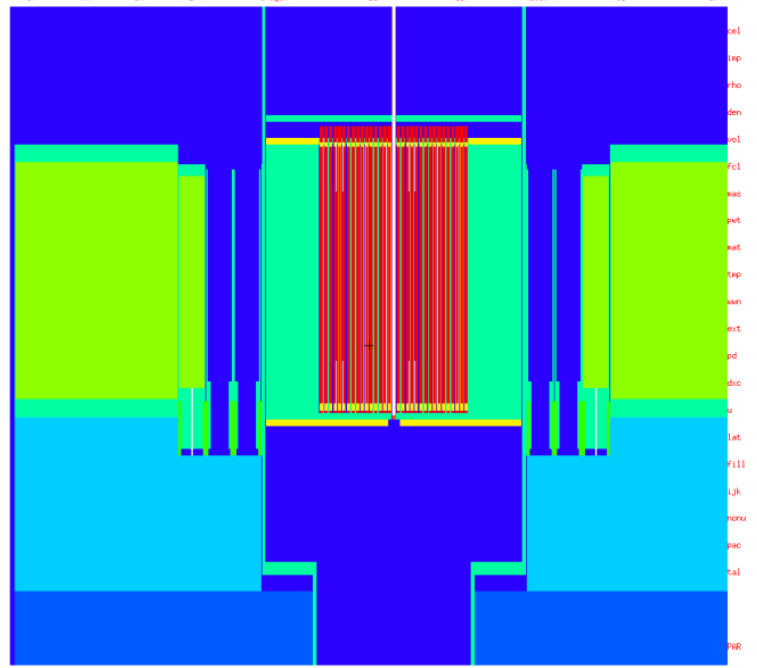

Fig. (6): MCNPX model side view of MINERVE core experimental and driver zone

\section{Results and Discussion}

The comparison of the calculated neutron spectrum shown in Figure (7) confirms the soft spectrum characteristics of $\mathrm{R} 2-\mathrm{UO} 2$ core, which is mentioned in Table (2). This is due to the over moderation of the R2-UO2 compared to R1-UO2 which is discussed in the details of their core configuration in a previous study [10]. The change in the thermal and fast neutron flux components between the cores induces a significant effect on the criticality calculation according to the used nuclear data library, and thus, influence the accuracy of the results in the two studied versions, ENDF/BVI.8 and ENDF/BVII.0, as will be shown later.

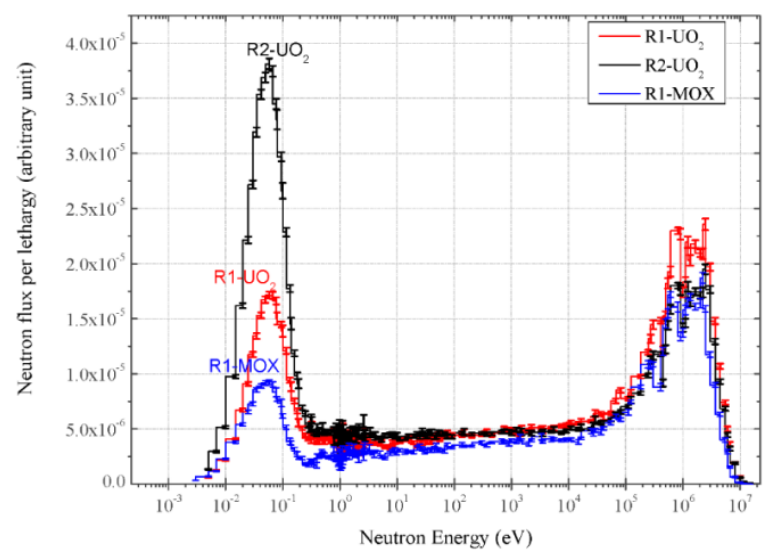

Fig. (7): Comparison between neutron spectra for the core configurations R1-UO2, R2-UO2, and R1-MOX [8]
The comparison between the calculated effective multiplication factor $k_{\text {eff }}$ in cases of R1-UO2, R2$\mathrm{UO} 2$, and R1-MOX configurations with OSMOSE samples, using ENDF/BVI.8 and ENDF/BVII.0 nuclear data is shown in Table (3). The majority of the results calculated with ENDF/BVI.8 were overestimated in case of the R1-UO2 with respect to ENDF/BVII.0, which can be noticed from the negative values of the relative difference. On the other hand, the results of ENDF/BVI.8 were underestimated in case of the $\mathrm{R} 2-\mathrm{UO} 2$ with respect to ENDF/BVII.0 as noticed from the positive values of the relative difference. These results show a strong dependence of the variation between ENDF/BVI.8 and ENDF/BVII.0 nuclear data on the neutron spectrum of the specified core. The ENDF/BVI.8 nuclear data tends to underestimate criticality in the soft spectrum core, while overestimate criticality in the relatively harder spectrum core (PWR spectrum).

The comparison between the calculated reactivity worth of OSMOSE samples in MINERVE for R1$\mathrm{UO} 2$, R2-UO2, and R1-MOX configurations is shown in Tables (4, 5, , and6, respectively), using ENDF/BVI.8 and ENDF/BVII.0 nuclear data. Additionally, the calculation results of the reactivity worth were compared with the available experimental data $[14,16]$ in cases of R1-UO2 and R1-MOX as shown in Figures (8 and 9). The calculated reactivity worth using ENDF/BVII.0 shows a considerable better agreement with the experimental results than when using ENDF/BVI.8. The minimum and maximum absolute relative difference between the experimental results and ENDF/BVII.0 calculations were $1 \%$ and $5 \%$ in case of R1-UO2, and, $1 \%$ and $8 \%$ in case of R1-MOX, respectively. A much larger deviation from the experimental results was observed upon using ENDF/BVI.8 nuclear data in the calculations, particularly in NP37_2, PU39, and PU42 samples in R1-UO2, and, NP37_1, PU42, and URE samples in R1MOX. The minimum and maximum absolute relative differences between the experimental results and ENDF/BVI.8 calculations were $8 \%$ and $132 \%$ in case of R1-UO2, and, $34 \%$ and $195 \%$ in case of R1-MOX, respectively. These results show a significant improvement in ENDF/BVII.0 nuclear data evaluation over ENDF/BVI.8, which was particularly evident in PU39, PU42, and U234 samples in case of R1-UO2, and, Unat and URE 
samples in case of R1-MOX, where the absolute relative difference between the experimental results and ENDF/BVII.0 calculations was reduced down to $1 \%$.

Other than the variation between the experimental and calculated results due to using different data libraries, it is also worth noting that OSMOSE samples may include other unspecified isotopes

Table (3): Effective multiplication factor with OSMOSE samples in MINERVE configurations

\begin{tabular}{|c|c|c|c|c|c|c|c|c|c|}
\hline \multirow[t]{3}{*}{ Sample } & \multicolumn{9}{|l|}{$k_{\text {eff }}$} \\
\hline & \multicolumn{3}{|l|}{ R1-UO2 } & \multicolumn{3}{|l|}{ R2-UO2 } & \multicolumn{3}{|l|}{ R1-MOX } \\
\hline & $\begin{array}{l}\text { ENDF/BVI } \\
.8 \\
\end{array}$ & $\begin{array}{l}\text { ENDF/BVI } \\
\text { I. } 0\end{array}$ & Rel. diff. \% & $\begin{array}{l}\text { ENDF/BVI } \\
.8 \\
\end{array}$ & $\begin{array}{l}\text { ENDF/BVI } \\
\text { I. } 0\end{array}$ & Rel. diff. \% & $\begin{array}{l}\text { ENDF/BVI } \\
.8 \\
\end{array}$ & $\begin{array}{l}\text { ENDF/BVI } \\
\text { I.0 }\end{array}$ & Rel. diff. \% \\
\hline AM41_1 & 1.00107 & 1.00004 & -0.10 & 1.00158 & 1.00202 & 0.04 & 0.99922 & 0.99881 & -0.04 \\
\hline AM41_2 & 1.00128 & 0.99918 & -0.21 & 1.00122 & 1.00200 & 0.08 & 0.99902 & 0.99817 & -0.09 \\
\hline AM43 & 1.00110 & 1.00013 & -0.10 & 1.00139 & 1.00199 & 0.06 & 0.99913 & 0.99893 & -0.02 \\
\hline NP37_1 & 1.00104 & 1.00020 & -0.08 & 1.00146 & 1.00178 & 0.03 & 0.99879 & 0.99898 & 0.02 \\
\hline NP37_2 & 1.00103 & 0.99939 & -0.16 & 1.00150 & 1.00232 & 0.08 & 0.99910 & 0.99821 & -0.09 \\
\hline PU38 & 1.00115 & 0.99958 & -0.16 & 1.00119 & 1.00195 & 0.08 & 0.99934 & 0.99873 & -0.06 \\
\hline PU39 & 1.00117 & 1.00111 & -0.01 & 1.00143 & 1.00214 & 0.07 & 0.99924 & 0.99978 & 0.05 \\
\hline PU40 & 1.00076 & 0.99953 & -0.12 & 1.00127 & 1.00181 & 0.05 & 0.99907 & 0.99860 & -0.05 \\
\hline PU41 & 1.00121 & 1.00073 & -0.05 & 1.00135 & 1.00219 & 0.08 & 0.99916 & 0.99943 & 0.03 \\
\hline PU42 & 1.00130 & 1.00014 & -0.12 & 1.00103 & 1.00224 & 0.12 & 0.99934 & 0.99893 & -0.04 \\
\hline $\mathrm{U} 233$ & 1.00110 & 1.00119 & 0.01 & 1.00156 & 1.00202 & 0.05 & 0.99942 & 0.99993 & 0.05 \\
\hline $\mathrm{U} 234$ & 1.00109 & 1.00013 & -0.10 & 1.00150 & 1.00216 & 0.07 & 0.99894 & 0.99895 & 0.00 \\
\hline Unat & 1.00122 & 1.00039 & -0.08 & 1.00116 & 1.00204 & 0.09 & 0.99930 & 0.99916 & -0.01 \\
\hline URE & 1.00117 & 1.00148 & 0.03 & 1.00128 & 1.00219 & 0.09 & 0.99904 & 1.00013 & 0.11 \\
\hline TH232 & 1.00108 & 1.00028 & -0.08 & 1.00136 & 1.00236 & 0.10 & 0.99907 & 0.99899 & -0.01 \\
\hline U-TH232 & 1.00141 & 0.99904 & -0.24 & 1.00145 & 1.00213 & 0.07 & 0.99901 & 0.99837 & -0.06 \\
\hline
\end{tabular}

Table (4): Reactivity worth of OSMOSE samples in MINERVE for R1-UO2 configuration

\begin{tabular}{llll}
\hline Sample & Reactivity worth $(\mathrm{pcm})$ & & \\
\cline { 2 - 4 } & ENDF/BVI.8 & ENDF/BVII.0 & $\mathrm{n} / \mathrm{a}$ \\
\hline AM41_1 & -14.97 & -34.98 & $\mathrm{n} / \mathrm{a}$ \\
AM41_2 & 5.99 & -121.05 & $\mathrm{n} / \mathrm{a}$ \\
AM43 & -11.97 & -25.99 & -19.58 \\
NP37_1 & -17.96 & -18.99 & -105.76 \\
NP37_2 & -18.96 & -100.02 & $\mathrm{n} / \mathrm{a}$ \\
PU38 & -6.98 & -81.00 & 72.34 \\
PU39 & -4.99 & 71.89 & $\mathrm{n} / \mathrm{a}$ \\
PU40 & -45.91 & -86.01 & $\mathrm{n} / \mathrm{a}$ \\
PU41 & -1.00 & 33.96 & -25.2 \\
PU42 & 7.98 & -24.99 & $\mathrm{n} / \mathrm{a}$ \\
U233 & -11.97 & 79.87 & -26.18 \\
U234 & -12.97 & -25.99 & $\mathrm{n} / \mathrm{a}$ \\
Unat & 0.00 & 0.00 &
\end{tabular}


EVALUATION OF ENDF/B-VI.8 AND ENDF/B-VII.0 .....

\begin{tabular}{llll}
\hline URE & -4.99 & 108.80 & $\mathrm{n} / \mathrm{a}$ \\
TH232 & -13.97 & -10.99 & $\mathrm{n} / \mathrm{a}$ \\
U-TH232 & 18.95 & -135.08 & $\mathrm{n} / \mathrm{a}$ \\
\hline
\end{tabular}

Table (5): Reactivity worth of OSMOSE samples in MINERVE for R2-UO2 configuration

\begin{tabular}{lll}
\hline Sample & Reactivity worth $(\mathrm{pcm})$ & \\
\cline { 2 - 3 } & ENDF/BVI.8 & ENDF/BVII.0 \\
\hline AM41_1 & 41.89 & -1.99 \\
AM41_2 & 5.99 & -3.98 \\
AM43 & 22.94 & -4.98 \\
NP37_1 & 29.92 & -25.90 \\
NP37_2 & 33.91 & 27.88 \\
PU38 & 2.99 & -8.96 \\
PU39 & 26.93 & 9.96 \\
PU40 & 10.97 & -22.91 \\
PU41 & 18.95 & 14.94 \\
PU42 & -12.97 & 19.91 \\
U233 & 39.89 & -1.99 \\
U234 & 33.91 & 11.95 \\
Unat & 0.00 & 0.00 \\
URE & 11.97 & 14.94 \\
TH232 & 19.95 & 31.86 \\
U-TH232 & 28.92 & 8.96 \\
\hline
\end{tabular}

Table (6): Reactivity worth of OSMOSE samples in MINERVE for R1-MOX configuration

\begin{tabular}{llll}
\hline Sample & Reactivity worth $(\mathrm{pcm})$ & & \\
\cline { 2 - 4 } & ENDF/BVI.8 & ENDF/BVII.0 & Experimental Results \\
\hline AM41_1 & -8.01 & -35.07 & -34.16 \\
AM41_2 & -28.05 & -99.26 & -96.31 \\
AM43 & -17.03 & -23.04 & $\mathrm{n} / \mathrm{a}$ \\
NP37_1 & -51.10 & -18.03 & -17.33 \\
NP37_2 & -20.03 & -95.25 & -97.57 \\
PU38 & 4.01 & -43.09 & $\mathrm{n} / \mathrm{a}$ \\
PU39 & -6.01 & 62.07 & 64.46 \\
PU40 & -23.04 & -56.13 & $\mathrm{n} / \mathrm{a}$ \\
PU41 & -14.02 & 27.04 & $\mathrm{n} / \mathrm{a}$ \\
PU42 & 4.01 & -23.04 & -24.2 \\
U233 & 12.02 & 77.07 & $\mathrm{n} / \mathrm{a}$ \\
U234 & -36.06 & -21.04 & -22.93 \\
Unat & 0.00 & 0.00 & $\mathrm{n} / \mathrm{a}$ \\
URE & -26.04 & 97.07 & 97.98 \\
TH232 & -23.04 & -17.03 & -17.23 \\
U-TH232 & -29.05 & -79.20 & n/a \\
\hline
\end{tabular}




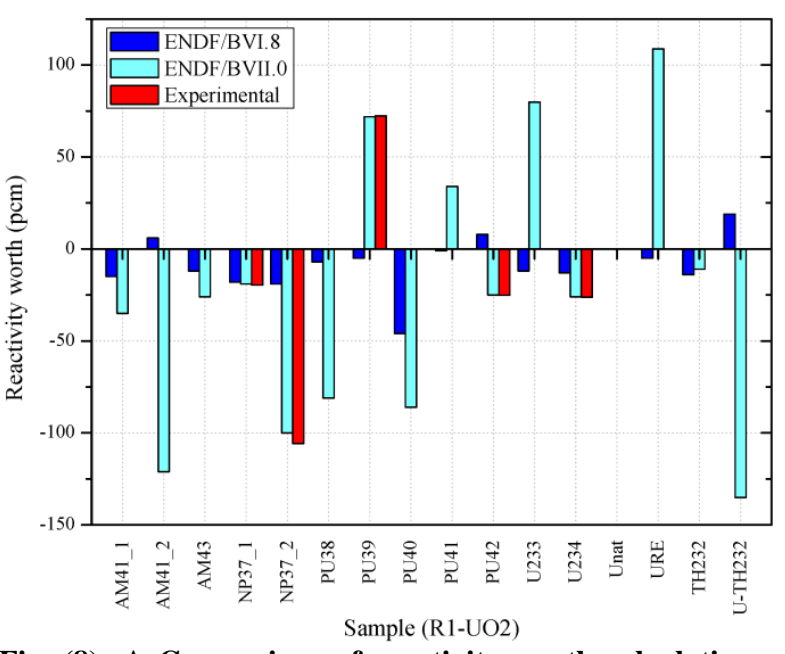

Fig. (8): A Comparison of reactivity worth calculations of OSMOSE samples with experimental results in R2-UO2 configuration

\section{Conclusion}

The present work investigated the effective multiplication factor and reactivity worth of MINERVE reactor with several OSMOSE samples in R1-UO2, R1-UO2, and R1-MOX core configurations. The investigation involved the comparison of the calculated effective multiplication factor using MCNPX code with ENDF/BVI.8 and ENDF/BVII.0 nuclear data libraries. Moreover, the difference between the calculated reactivity worth by ENDF/BVI.8 and ENDF/BVII.0 was examined using available experimental results of the relevant core.

The comparison of the calculated effective multiplication factor using ENDF/BVI.8 and ENDF/BVII.0 nuclear data libraries showed the tendency of ENDF/BVI.8 to underestimate criticality with respect to ENDF/BVII.0 in the soft spectrum core, while overestimate criticality in the relatively harder spectrum core. The comparison between the experimental and calculated reactivity worth of OSMOSE samples in R1-UO2 and R1MOX core configurations using ENDF/BVII.0 and ENDF/BVI.8 nuclear data libraries, showed a considerable improvement in ENDF/BVII.0 evaluation. This improvement is owing to a better accuracy in the cross-sections and fission yield products, especially in PU39, PU42, and U234 samples in case of R1-UO2, and, Unat and URE samples in case of R1-MOX of the relatively harder neutron spectrum.

Further investigations and comparisons are required for more recent nuclear data libraries

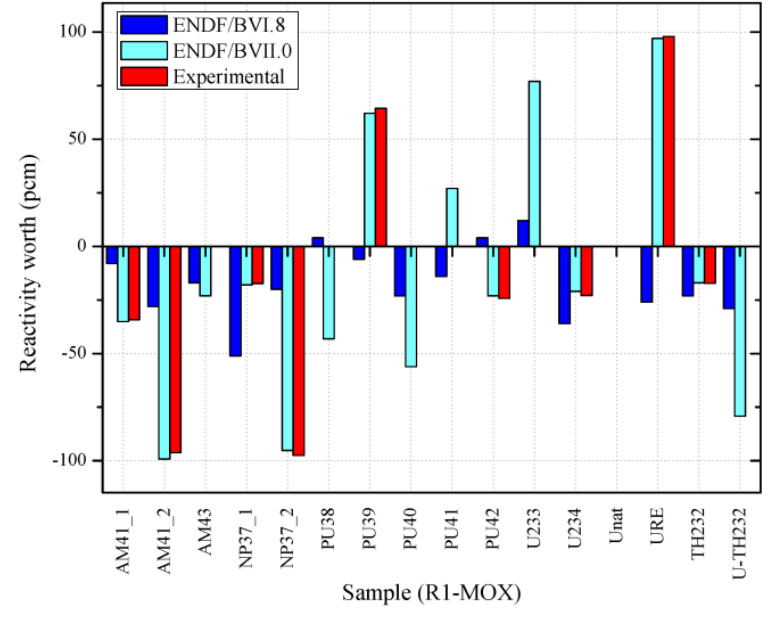

Fig. (9): A Comparison of reactivity worth calculations of OSMOSE samples with experimental results in R1-MOX configuration

including ENDF/BVII.1 and ENDF/BVIII.0 in a more variety of neutron spectra, which will advance performance, and reliability of the evaluated nuclear data libraries.

\section{Acknowledgment}

The author appreciates the valuable remarks provided by Dr. Noura Hafez, which positively added to the quality of this research.

\section{References}

1. G. Pandikumar, V. Gopalakrishnan and P. Mohanakrishnan, "Impact of spread in minor actinide data from ENDF/B-VII.0, ENDF/BVI.8, JENDL-3.3 and JEFF-3.0 on an IAEACRP FBR benchmark for MA incineration," Annals of Nuclear Energy, vol. 35, pp. 15191534, 2008.

2. G. Ilas, I. C. Gauld and G. Radulescu, "Validation of new depletion capabilities and ENDF/B-VII data libraries in SCALE," Annals of Nuclear Energy, vol. 46, pp. 43-55, 2012.

3. O. Cabellos, V. Fusco, C. J. D. Obra, J. S. Martinez, E. Gonzalez, D. Cano-Ott and F. Alvarez-Velarde, "Testing JEFF-3.1.1 and ENDF/B-VII.1 decay and fission yield nuclear data libraries with fission pulse neutron emission and decay heat experiments," Nuclear Data Sheets, vol. 118, pp. 472-475, 2014.

4. I. C. Gauld, M. T. Pigni and G. Ilas, "Validation and testing of ENDF/B-VII decay 
data," Nuclear Data Sheets, vol. 120, pp. 33 36, 2014.

5. I. C. Gauld, M. L. Williams, F. M. Sendis and J. S. Martinez, "Integral nuclear data validation using experimental spent nuclear fuel compositions," Nuclear Engineering and Technology, vol. 49, pp. 1226-1233, 2017.

6. L. Maul, "Analysis of different nuclear data libraries on the fluoride-salt-cooled hightemperature reactor," Nuclear Engineering and Design, vol. 335, pp. 314-325, 2018.

7. G. Stoven, R. Klann and Z. Zhong, "OSMOSE program: Statistical review of oscillation measurements in the MINERVE reactor R1UO2 configuration," Office of Scientific and Technical Information (OSTI), ANL, Argonne, IL, United States, 2007.

8. H. Shahbunder, N. H. Hafez, S. U. ElKameesy and E. H. Amin, "Study of the basic safety characteristic parameters of the MINERVE reactor core configurations," International Journal of Nuclear Energy Science and Technology, vol. 9, pp. 186-200, 2015.

9. H. Shahbunder and N. Hafez, "Effects of Am and $\mathrm{Cm}$ distributions on neutronic parameters of MINERVE reactor," Progress in Nuclear Energy, vol. 98, pp. 123-130, 2017.

10. H. Shahbunder, E. H. Amin, S. U. ElKhameesy and N. H. Hafez, "MCNPX calculation of the reactivity worth of actinides OSMOSE samples," Annals of Nuclear Energy, vol. 80, pp. 70-76, 2015.

11. R. Klann, G. Perret, J. P. Hudelot and M. Antony, "Modeling report of the CEA cadarache MINERVE reactor for the OSMOSE project.," Office of Scientific and Technical Information (OSTI), Argonne, 2005 .
12. P. Fougeras, A. Chabre and C. Mergui, "The place of EOLE, MINERVE and MASURCA facilities in the R\&D activities of the CEA," in Joint Meeting of the National Organization of Test Research and Training Reactors (TRTR), and the International Group on Research Reactors (IGORR), Gaithersburg, MD, USA, September 12-16, 2005.

13. J. P. Hudelot, C. Chabert, J. P. Chauvin, P. Fougeras, G. Perret, X. Genin, C. Leorier and J. M. Moulinier, "The OSMOSE experimental program in MINERVE for the qualification of the integral cross sections of actinides," Journal of Nuclear Science and Technology, vol. 39, pp. 1077-1080, 2002.

14. Z. Zhong and R. T. Klann, "Reactivity-worth estimates of the OSMOSE samples in the MINERVE reactor R1-MOX, R2-UO2 and MORGANE/R configurations," Office of Scientific and Technical Information (OSTI), Argonne, 2007.

15. G. Aliberti and R. Klann, "OSMOSE experiment representativity studies.," Office of Scientific and Technical Information (OSTI), Argonne, 2007.

16. R. T. Klann, G. Aliberti, Z. Zhong, D. Graczyk and A. Loussi, "OSMOSE an experimental program for improving neutronic predictions of advanced nuclear fuels.," Office of Scientific and Technical Information (OSTI), Argonne, 2007.

17. D. B. Pelowitz, "MCNPX user's manual version 2.7.0," New Mexico, U.S., 2011.

18. P. F. Rose, "ENDF-201: ENDF/B-VI summary documentation," Office of Scientific and Technical Information (OSTI), Upton, 1991.

19. M. B. Chadwick, et al., "ENDF/B-VII.0: Next generation evaluated nuclear data library for nuclear science and technology," Nuclear Data Sheets, vol. 107, pp. 2931-3060, 2006. 